\title{
Suppression of Classical Flutter using a 'Smart Blade'
}

\author{
G. Politakis ${ }^{1}$, W. Haans ${ }^{2}$ and G.J.W van Bussel $^{3}$ \\ Delft University of Technology, Delft, 2629HS, The Netherlands
}

\begin{abstract}
Future horizontal axial wind turbines that approach the 10MW capacity will have a rotor diameter somewhere in the order of $170 \mathrm{~m}$. Their loads could be much higher and their blades more flexible compared to current multi-MW wind turbines, most probably resulting in aeroelastic instabilities not commonly seen in the machines of today. The likely design drivers for future 10MW+ wind turbines are fatigue life and aeroelastic stability. To help improve the fatigue life and the aeroelastic stability, load control could be applied to future wind turbines. This paper concerns the load control concept of an actuated trailing edge flap (TEF), focusing on the effects they have on the aeroelastic stability of a blade. In particular, the two degree of freedom Flap-Torsion Flutter instability-Classical Flutter- is studied. A modal representation of the turbine dynamics (eigenmodes and eigenfrequencies), an unsteady BEM model and a simple controller for the actuated trailing edge are coupled to form an aero-servo-elastic model. Its unsteady airfoil model is based on Theodorsen's theory, modified to include the effects of unsteady trailing edge flap deflections. The aeroservo-elastic model of the wind turbine is designed with the intention to capture the Classical Flutter instability. It is demonstrated that an extension of the stable operating range beyond the original Flutter limit is feasible when using an actuated trailing edge flap, combined with a simple controller.
\end{abstract}

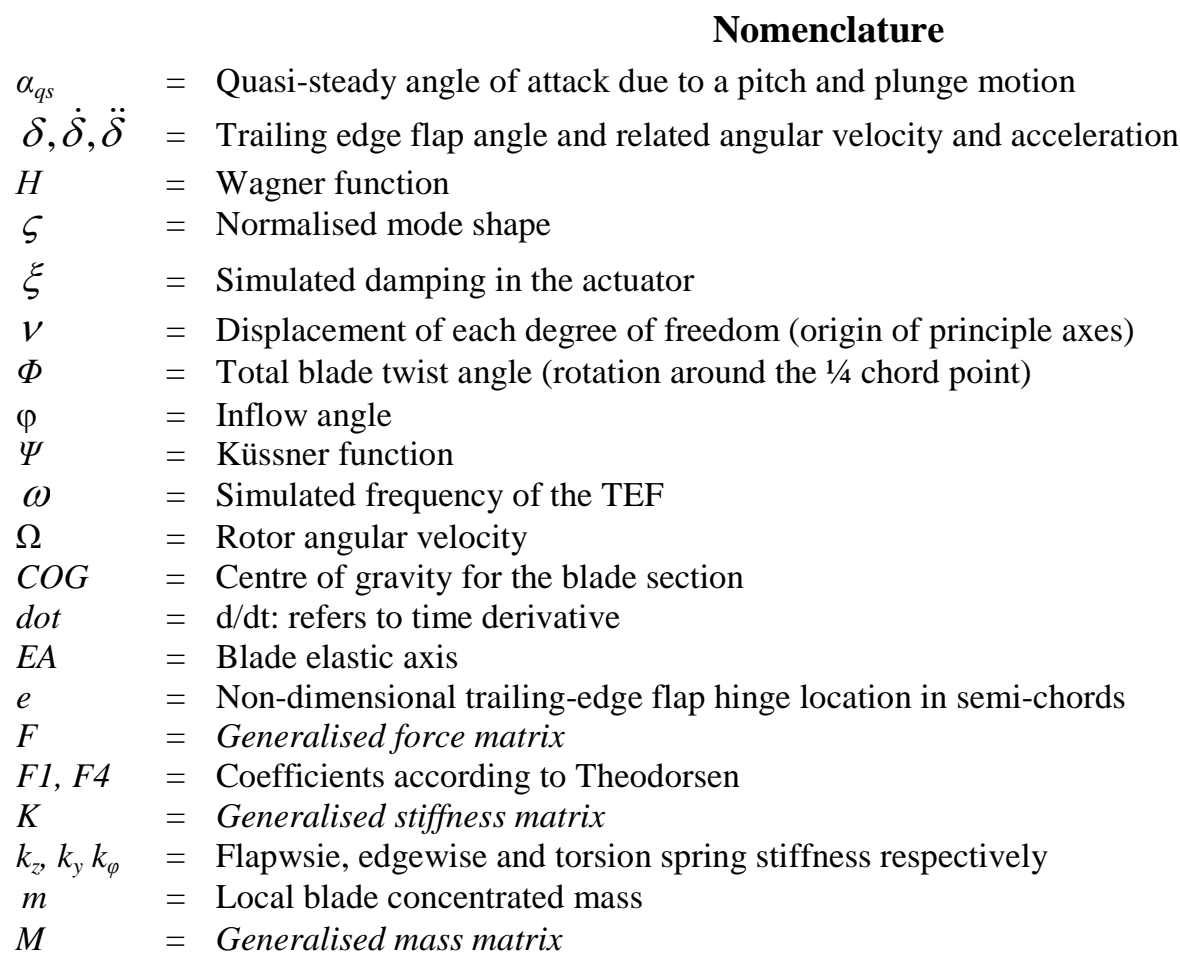

\footnotetext{
${ }^{1}$ Student, Faculty of Aerospace Engineering, Kluyverweg 1, 2629HS, Delft, The Netherlands, No membership ${ }^{2} \mathrm{PhD}$ Student, Faculty of Aerospace Engineering, Kluyverweg 1, 2629HS, Delft, The Netherlands, Member.

3 Associate Professor, Faculty of Aerospace Engineering, Kluyverweg 1, 2629HS, Delft, The Netherlands, No membership 


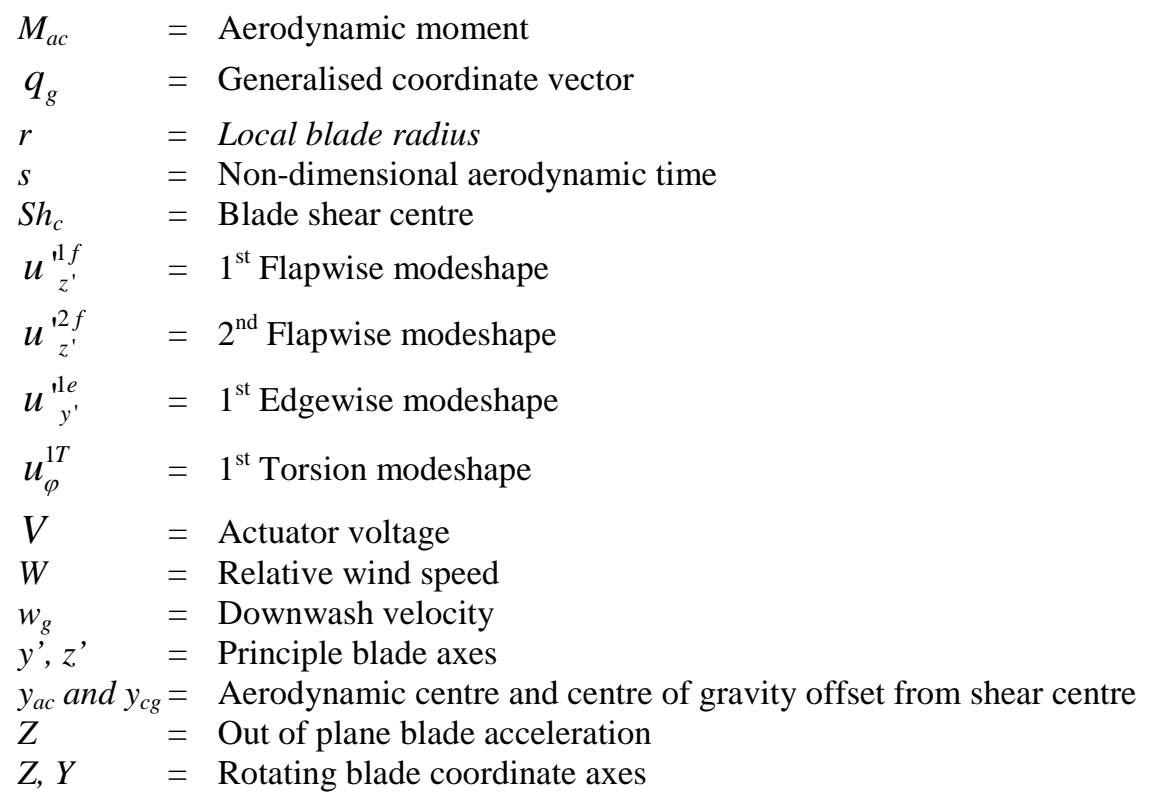

\section{Introduction}

\section{A. Background}

The mechanics and understanding of aeroelastic instabilities is particularly important in relation to the next generation of wind turbine designs. With current 3-5MW wind turbines entering a mature phase in terms of technological advancement, a logical direction for further success in the industry could be to develop machines larger than 5MW. Sizes approaching the 10MW capacity will have a rotor diameter somewhere in the order of $170 \mathrm{~m}$. Even 20MW machines, with a diameter well over 200m, have been conceptualised. This means much higher loads and more flexible blades than current MW wind turbines, most probably resulting in aeroelastic instabilities not commonly seen in the current machines of today.

The likely design drivers for future 10MW+ wind turbines are fatigue life and aeroelastic stability. To help improve the fatigue life and the aeroelastic stability, load control could be applied to future wind turbines. Load control could be defined as the act of controlling wind turbine loads through deliberate modification of the rotor characteristics during operation. Next to improved fatigue life and aeroelastic stability, load control could also serve to reduce extreme loads

Aeroelastic stability of a wind turbine refers to the dynamic response of the various components of a wind turbine (blades, tower, etc) given an external loading condition. In short, aerodynamics is dependent on structural response of the wind turbine, while the structural response is dependent on the aerodynamics; thus, such a coupling has the potential to lead to undesirable system dynamics under certain conditions. The tower motion, blade accelerations, etc. can be in a mode where the phase of the aerodynamic response is conducive to drawing energy from the wind into the system and causing undesirable violent vibrations-and most likely failure ${ }^{1}$.

Two common such instabilities exhibited by rotating aerodynamic machines are the Flap-Lag and Classical Flutter instability. Classical Flutter is considered in this study over the Flap-Lag instability because it is considered to perhaps be a greater barrier to wind turbine design in the future. With current design trends, it may be that $10 \mathrm{MW}+$ wind turbines will be more flexible in torsion and thereby increase the chance of Flutter occurring ${ }^{6}$. A danger is that Flutter occurs in attached flow ${ }^{2}$ and therefore poses a real threat in normal operating conditions for a wind turbine. In contrast to the Flap-Lag instability (a stall induced phenomenon), there is no limit cycling dynamics (the stalling and un-stalling of the blade) to periodically stabilise the system ${ }^{10}$, and as such, vibrations quickly grow in magnitude. There are no post-design solutions to the Flutter problem so careful analysis is needed at the design stage to avoid these instabilities ${ }^{2}$. It is left for other studies to test the merit of using TEFs for control of the Flap-Lag instability. 
Classical Flutter is the term used to describe the dynamics of a blade undergoing coupled vibrations in the flapwise and torsional mode. Unlike the FlapLag instability, Flutter occurs in the region where flow is attached to the

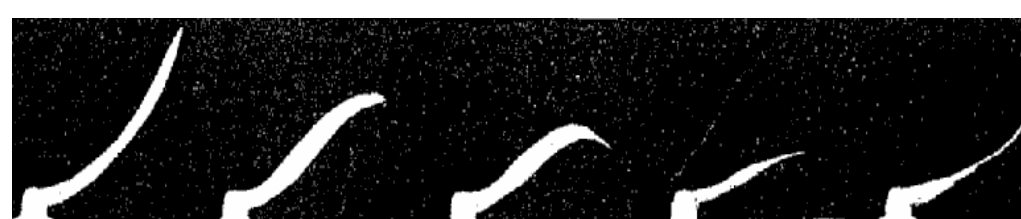

Figure 1. Blade Flutter mode over one period of oscillation ${ }^{3}$. blade and aerodynamic forces vary linearly with angles of attack ${ }^{2}$. From the work of Hansen ${ }^{3}$, Figure 1 illustrates a blade in a flutter mode, where the blade bending and torsion modes over a cycle of vibration are clearly evident. Aerodynamic coupling can occur and these modes can feed each other and grow in amplitude very rapidly. To explain the coupling mechanism, pitch or torsional deflections in the aerofoil section cause fluctuations in lift, causing the blade to flap, which in turn acts as an exciter for torsion through a changing angle of attack ${ }^{4}$ When the lift and vertical motion of the blade are both working in the same direction (since vertical motion adds a torsion moment due to blade centre of mass offset), work is being added to the system. When the lift opposes the motion, energy is being extracted, effectively damping the system. Therefore Flutter can occur when the timing of torsion and flap motion is such that the lift over one cycle of motion is aligned with the flap motion. An important coupling factor in this is the location of the centre of mass (COM) from the blade elastic shear centre. It has been shown that depending on the location of COM, Flutter limits are changed ${ }^{3}$.

Classical Flutter has not been the cause of any failures to date in wind turbines, rather it being more prevalent in rotorcraft applications ${ }^{5}$. However, with a likely reducing blade torsional stiffness with increasing blade radius (considering current design trends), it is possible the stability limit (condition at which Flutter occurs, i.e. for a given blade tip speed) between the turbines of now, and those of the future, is becoming narrower ${ }^{6}$.

To this end, the motivator for undertaking the present analysis of Flutter suppression using actuated trailing edge geometry is to assess a possible solution for manufacturers wishing to tackle the stability problem that will inevitably ensue. It is certainly desirable to know if Classical Flutter needs to be taken into account and what can be done to mitigate its effects.

\section{B. Research aims \& objectives}

Promising results for load reduction potential using actuated trailing edge flaps have been shown ${ }^{19}$. The present analysis however focuses on their use as an aeroelastic stability-shaping device. The primary aim of this study is to investigate the Classical Flutter instability limit margins of today's largest wind turbines-5MW machines with rotor diameters approximately of $120 \mathrm{~m}$ and show in theory, that actuated trailing edge flaps can provide a solution to combat this problem. This is achieved through the following set of sub-objectives to:

1. Set-up a simplified aeroelastic model of a wind turbine with a rigid hub, including the dynamic effects of trailing edge geometry (Section II)

- Aerodynamic Model (lift coefficient) based on Theodorsen's theory for a flat plate aerofoil

- Structural model based on a modal (eigenmode and eigenfrequency) representation of the total length of blade

- Blade Element Momentum (BEM) theory for determining blade forces

2. Determine the operating conditions under which Flutter can be induced (Section II)

3. Implement a basic controller for a defined trailing edge flap actuator and control surface geometry assembly specifically for the intention of suppressing Flutter (Section III)

\section{Aeroelastic Model for Investigating Classical Flutter}

\section{A. Modelling Assumptions}

A thorough investigation into the behaviour of wind turbines operating in an unsteady environment demands a full aeroelastic analysis comprising of interactions starting at the rotor and cascading on down through the nacelle and tower foundation. For the current investigation into the classical Flutter occurrence, a simplified approach has been adopted however, because here we are trying to isolate the instability and test only for the feasibility of using TEFs to avoid Flutter. The wind turbine represented here assumes an infinitely stiff tower with the rotor blades fixed to a rigid hub (no hinge offset). Furthermore, the rotor blade rotating axes are assumed to coincide with the rotational plane, i.e. pre-cone angle equal to zero and the rotor plane orientated perpendicular to the wind field, i.e. tilt angle equal to zero (avoidance of yawed flow conditions in normal turbine operation). A further simplification is 
that only one blade is modeled; multiple blade interaction effects are neglected, which should make the dynamics and effects of an actuated control flap more transparent.

The blade used for the initial development of the model is that from the UpWind project ${ }^{4}$. This wind turbine is based on a $5 \mathrm{MW}$, three bladed design with a rotor diameter of $126 \mathrm{~m}$ and rated speed of 12.5RPM. The UpWind project is a joint European investigation into the design of the next generation of wind turbines up to and beyond 10MW. The UpWind turbine is a fabricated design using characteristics taken from existing commercial designs.

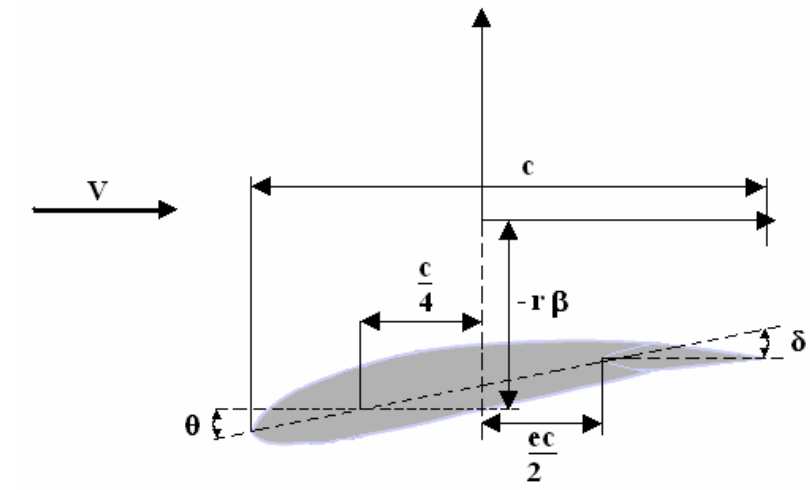

\section{B. Aerodynamic Model}

Figure 2. Blade section showing trailing edge flap and geometric definitions.

The rotor aerodynamics is modeled with a Blade Element Momentum (BEM) model. The axial induction factor is assumed to be constant over an entire annulus; an empirical tip loss model is not included. The effect of wake rotation is neglected as well. Dynamic inflow is modeled however with a first order differential equation and the BEM model also accounts for the turbulent wake state.

Airfoil lift is determined using Theodorsen's unsteady airfoil model ${ }^{10}$, the drag and moment coefficients were determined via lookup tables for the UpWind blade. Dynamic stall is not modeled. Not having dynamic stall is not a major issue for this study, since the Classical Flutter phenomenon occurs in attached flow conditions.

The non-circulatory and circulatory lift coefficients, $c_{1, n c}$ and $c_{1, c}$, respectively, are summed to arrive at the total lift coefficient $\mathrm{c}_{1}$,

$$
c_{l}=c_{l, n c}+c_{l, c} .
$$

Theodorsen's model is modified by Leishman ${ }^{7}$ to not only account for arbitrary airfoil motion in an arbitrary wind gust field, but also include arbitrary trailing edge deflection. These components are described by the quasi-steady angle of attack of the aerofoil $\alpha_{q s}$ and the trailing edge flap deflection $\delta$ according to the definitions and geometry in Figure 2. $\alpha_{q s}$ is given by Eq. (2),

$$
\alpha_{q s}=\varphi+\Delta \varphi-\left(\Phi+\frac{\dot{\Phi} c}{2 W}+\frac{\dot{Z}}{W}\right)
$$

where $\varphi$ is the inflow angle, $\Delta \varphi$ is the incremental inflow angle, $W$ is the relative wind speed, $\Phi$ is the total blade twist angle (rotation around the $1 / 4$ chord point) and $Z$ is the out of plane blade acceleration. The dotsuperscript denotes the time derivative. $\mathrm{c}_{\mathrm{l,nc}}$ is given by Eq. (3),

$$
c_{l, n c}=-\frac{\pi c}{2 W^{2}}\left(\ddot{Z}+W \dot{\Phi}+\frac{\Omega}{W} \dot{\Omega} r^{2} \alpha_{q s}+\frac{c \ddot{\Phi}}{4}\right)-\frac{c}{2 W^{2}}\left(F_{4} W \dot{\delta}+\frac{c F_{1} \ddot{\delta}}{2}\right)
$$

With $c$ being the chord length and $F 1$ and $F 4$ are coefficients according to Theodorsen, given by eg. Leishman ${ }^{7}$ $e$ is defined as the non-dimensional trailing-edge flap hinge location and is used in the coefficients. $\mathrm{c}_{\mathrm{l}, \mathrm{c}}$ is given in Eq. (4) via Duhamel's superposition integral with the Wagner indicial step response $H$ and the Küssner gust entry function $\Psi$,

$$
\begin{aligned}
c_{l, c}= & \left(c_{l, c}\right)_{\alpha}+\left(c_{l, c}\right)_{\delta}+\left(c_{l, c}\right)_{w_{g}} \\
= & 2 \pi\left(\alpha_{q s}(0) \mathrm{H}(s)+\frac{1}{V} \int_{0}^{s} \frac{d\left(V \alpha_{q s}\right)}{d \sigma} \mathrm{H}(s-\sigma) d \sigma+\delta_{q s}(0) \mathrm{H}(s)+\int_{0}^{s} \frac{d \delta_{q s}}{d \sigma} \mathrm{H}(s-\sigma) d \sigma+\frac{w_{g}(0)}{W} \Psi(s)\right. \\
& \left.+\int_{0}^{s} \frac{d w_{g}}{d \sigma} \Psi(s-\sigma) d \sigma\right)
\end{aligned}
$$

\footnotetext{
${ }^{4}$ www.upwind.eu
} 
where $s$ is the non-dimensional aerodynamic time and $w_{g}$ is the downwash velocity. The aforementioned relationships are provided in state-space format and solved using an indicial approximation method. A full account of the derivations is given in the work of Leishman?

\section{Structural Model - Method of Generalised Coordinates \& Virtual Work}

Table 1. UpWind Blade Eigenfrequencies.

\begin{tabular}{|c|c|}
\hline $\begin{array}{c}\text { Blade Eigenmodes - } \\
\text { Degrees of Freedom }\end{array}$ & $\begin{array}{c}\text { Eigenfrequency } \\
(\mathbf{H z})\end{array}$ \\
\hline $1^{\text {st }}$ Flapwise & 0.85 \\
\hline $2^{\text {nd }}$ Flapwise & 2.30 \\
\hline $1^{\text {st }}$ Edgewise & 1.20 \\
\hline $1^{\text {st }}$ Torsion & 5.60 \\
\hline
\end{tabular}

A modal approach is employed wherein the rotor blade is represented as a cantilever beam, which has both a distributed mass and stiffness and inbuilt twist about the radial axis. A modal analysis makes use of such a beam that is loaded to determine the deflections, velocities and inertias using generalised coordinates, which define the amount of structural displacement according to specified mode shapes of the beam that depend on its structural properties.

Currently, the first and second flapwise, first edgewise and first torsion modes are implemented. Most of the work done in bending is captured in the first two-three eigenmodes (lowest natural frequencies), and decreases for higher ones. The eigenmodes are determined according to the Stodola iteration procedure ${ }^{8}$. The modes are normalized to a tip deflection of one. Table 1 gives the derived blade eigenfrequencies for relevant eigenmodes. According to the generalised coordinate approach, the generalised deflections are computed by the summation of each eigenmode (superposition principle) times the corresponding generalised coordinate ${ }^{9}$

$$
v\left(x^{\prime}\right)=q_{g}(t) \cdot \varsigma\left(x^{\prime}\right)
$$

where $q_{g}$ is the generalised coordinate vector, $\varsigma$ is the corresponding normalised mode shape vector for the DOF of concern and $v$ is the displacement of each DOF. For the dynamics considered in the present study,

$$
\varsigma\left(x^{\prime}\right)=\left[\begin{array}{c}
u_{z^{\prime}}^{\prime f}\left(x^{\prime}\right) \\
u_{z^{\prime}}^{\prime 2 f}\left(x^{\prime}\right) \\
u_{y^{\prime}}^{\prime l e}\left(x^{\prime}\right) \\
u_{\varphi}^{1 T}\left(x^{\prime}\right)
\end{array}\right],
$$

where, $u_{z^{\prime}}^{1 f}, u_{z^{\prime}}^{\prime 2 f}, u_{y^{\prime}}^{\prime 1 e}$, and $u_{\varphi}^{1 T}$ correspond to the blade nodal displacements from the contributions of the 1st $\&$ 2nd flapwise, 1st edgewise and 1st torsion modes at frequencies presented in Table 1 and given in the rotating blade axes.

Figure 3 shows the blade coordinate systems and relevant structural parameters used in the model. The dynamic model requires rotational inertias to be specified for the blade as well as structural properties defining the extra inertias due to misalignment of the blade section centre of gravity $\left(\mathrm{y}_{\mathrm{cg}}\right)$ and aerodynamic centre $\left(\mathrm{y}_{\mathrm{ac}}\right)$ to the shear centre $\left(\mathrm{Sh}_{\mathrm{c}}\right)$. To simplify the structural coupling, the model assumes the flapwise and torsion spring to coincide at the elastic axis (EA), which is at the origin of the principle axes $\left(\mathrm{y}^{\prime}, \mathrm{z}^{\prime}\right)$ as depicted in Figure 3. The torsion moment is measured about the EA and includes moment contributions due to $y_{c g}$ and $y_{a c}$ offset from shear axis.

The structural characteristics relevant for the Classical Flutter model as depicted in Figure 3 are:

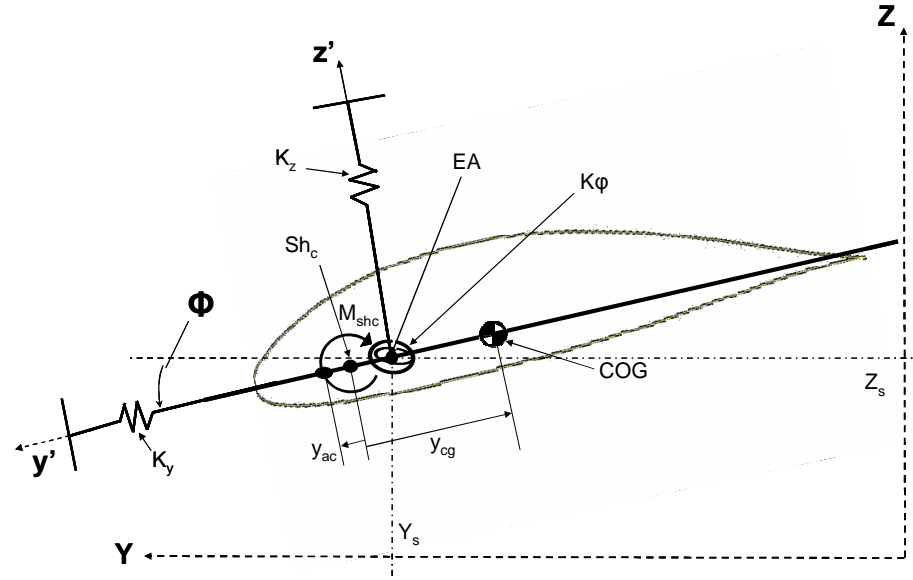

Figure 3. Blade Section Structural Characteristics Used in Dynamic Model (perspective given for arbitrary blade bending in $\mathrm{Y}$ and $\mathrm{Z}$ )defintions. 
- EA is the elastic axis (origin of principle axes)

- $y^{\prime}, z^{\prime}$ are the principle blade axes

- $Z_{\mathrm{s}}$ and $\mathrm{Y}_{\mathrm{s}}$ are the blade section deflections of the EA in the rotating blade coordinate axes

- $\mathrm{M}_{\mathrm{ac}}$ is the aerodynamic moment

- $\mathrm{COG}$ is the centre of gravity for the blade section

- $\mathrm{Sh}_{\mathrm{c}}$ is the shear centre - defined as where an in-plane force does not rotate the aerofoil ${ }^{9}$

- $\mathrm{y}_{\mathrm{ac}}$ and $\mathrm{y}_{\mathrm{cg}}$ ( $\mathrm{y}$ positive towards leading edge) are the distances of the aerodynamic moment and centre of gravity from the shear centre respectively

- $\mathrm{k}_{\mathrm{z}}, \mathrm{k}_{\mathrm{y}}$ and $\mathrm{k}_{\varphi}$ represent the flap, edgewise and torsion spring stiffness respectively

The blade deflection in the principle axes ( $\left.\mathrm{z}^{\prime}, \mathrm{y}^{\prime}\right)$ has components in both the in-and-out of plane directions (Y, $Z$ ). Due to non-zero twist angle- $\Phi$ along the blade span (changing in time), a coupling effect arises. For an accurate account of the flutter problem, it is desirable to include this coupling and can be done so using a trigonometric transformation on the curvatures of the elastic axis to the rotating blade axes $(\mathrm{Z}, \mathrm{Y})$. The deflection correction functions applied for the transformation are given by Bielawa ${ }^{10}$, which, through a series of partial integrations, couples the in-and-out of plane modes, while also accounting for the effects of time varying elastic torsion.

$$
\begin{aligned}
& \frac{d^{2} Z}{d X^{2}}=\frac{d^{2} z^{\prime}}{d x^{\prime 2}} \operatorname{Cos} \Phi-\frac{d^{2} y^{\prime}}{d x^{\prime 2}} \operatorname{Sin} \Phi \\
& \frac{d^{2} Y}{d X^{2}}=\frac{d^{2} z^{\prime}}{d x^{\prime 2}} \operatorname{Sin} \Phi-\frac{d^{2} y^{\prime}}{d x^{\prime 2}} \operatorname{Cos} \Phi
\end{aligned}
$$

The principle of virtual work is applied to formulate the generalized mass $[M]$, stiffness $[K](4 \mathrm{x} 4$ matrices) and force $[F]$ matrices for each degree of freedom in the dynamic equations, which takes the form Eq. (8)

$$
\left[M_{4 x 4}^{\prime}\right] \ddot{q}_{g}+\left[K_{4 x 4}^{\prime}\right] q_{g}=\left[F_{1 x 4 \text { ext }}^{\prime}(t)\right]
$$

The couplings required to capture the flutter mechanism are included in the matrices and appear as off-diagonal terms. The principal coupling mechanism included in the generalized mass matrix is the centre of gravity offset from the elastic shear centre. This serves as a mass coupling system (static mass moments) between the included flap and torsional mode displacements in time. In modal form, this coupling is represented by the matrix entry of Eq. (9),

$$
M_{1,4}=M_{4,1}=\int_{0}^{R} m\left(x^{\prime}\right) y_{c g} u_{\varphi}^{1 T}\left(x^{\prime}\right) u_{z^{\prime}}^{1 f}\left(x^{\prime}\right) d x^{\prime}
$$

where $m$ is the local mass.

The model proposed in this study also included interaction between the first torsion and second flapwise mode, which is similarly represented by Eq. (9).

The coupling in the stiffness matrix concerns an induced moment about the elastic axis (moment arm from centre of gravity offset) caused by the blade curvature introduced due to flapwise bending. The moment occurs due to the centrifugal force having a component perpendicular to the elastic axis acting at the centre of gravity ${ }^{10}$. Likewise, a torsion deflection induces a spanwise moment due to the centre of gravity being lifted out of the rotor plane. In virtual work form, these coupling are given by Eq. (10) and Eq. (11), respectively:

$$
K_{1,4}=\int_{0}^{R}\left\{m(x) \cdot \Omega^{2} \cdot r \cdot y_{c g} \cdot\left[u_{z}^{1 f}(x)^{\prime}\right]\right\} \cdot u_{\varphi}^{1 T} d x^{\prime}
$$

and,

$$
K_{4,1}=\int_{0}^{R}\left\{m(x) \cdot \Omega^{2} \cdot r \cdot y_{c g} u_{\varphi}^{1 T}(x) \cdot\left[u_{z}^{1 f}(x)^{\prime}\right]\right\} \cdot u_{z^{\prime}}^{1 f} d x^{\prime}
$$


where $u_{z}^{1 f}(x)$ is the flapwise bending slope due to deflection, $\Omega$ is the rotor angular velocity and $r$ is the blade radius. The coupling between the first torsion and second flapwise mode is represented similarly (i.e. $K_{2,4}$ and $K_{4,2}$ ).

The equations of motion (8) are solved with the Runge-Kutta-Nystrom time-integration method. The solution $\left(q_{g}\right)$ to the dynamic equations represents the amplitude of each vibration mode at each time-step. The deflections are then found according to Eq. (5). The aeroelastic model was validated against the ECN (Netherlands Energy Rresearch Centre) Blademode code ${ }^{11}$.

\section{UpWind Turbine Blade Classical Flutter Limits}

The stability limit at given turbine operating conditions is most often measured as a function of dynamic pressure, which can be related to tip speeds of the blade and hence to the rotor angular velocity at point of instability. The 'Brute Force' method is employed here to induce Flutter; as it is rather simple to employ in the aeroelastic model. Because of rotor dynamics having gravity effects as a function of its rotational frequency, a sinusoidal varying forcing function already exists in the dynamic equations to perform the frequency sweep of the system. The gravity force therefore acts an exciter for the Flutter mode, which at some frequency (equivalent to a blade tip speed) will merge flap and torsion modes to cause the Flutter mode.

The gravitational force can be swept over a frequency range by allowing the rotor to gradually speed up. The ramp up rate of the rotor angular velocity $\Omega$ is specified such that it does not induce unsteady rotor aerodynamics. A similar technique was used in other Flutter studies $^{12}$.

A rotor, with blade centre of gravity locations and other relevant structural parameters equal to those of the original UpWind turbine, is allowed to gradually speed up in time for a mean wind speed of $10 \mathrm{~ms}^{-1}$. Figure 4 presents the deflections in the flapwise and torsion directions (top plot) and the associated blade tip speed (bottom plot) as a function of time for a blade experiencing "Classical Flutter". For convenience, the time history prior to that shown has been omitted, and only that given is where Flutter is evident. The
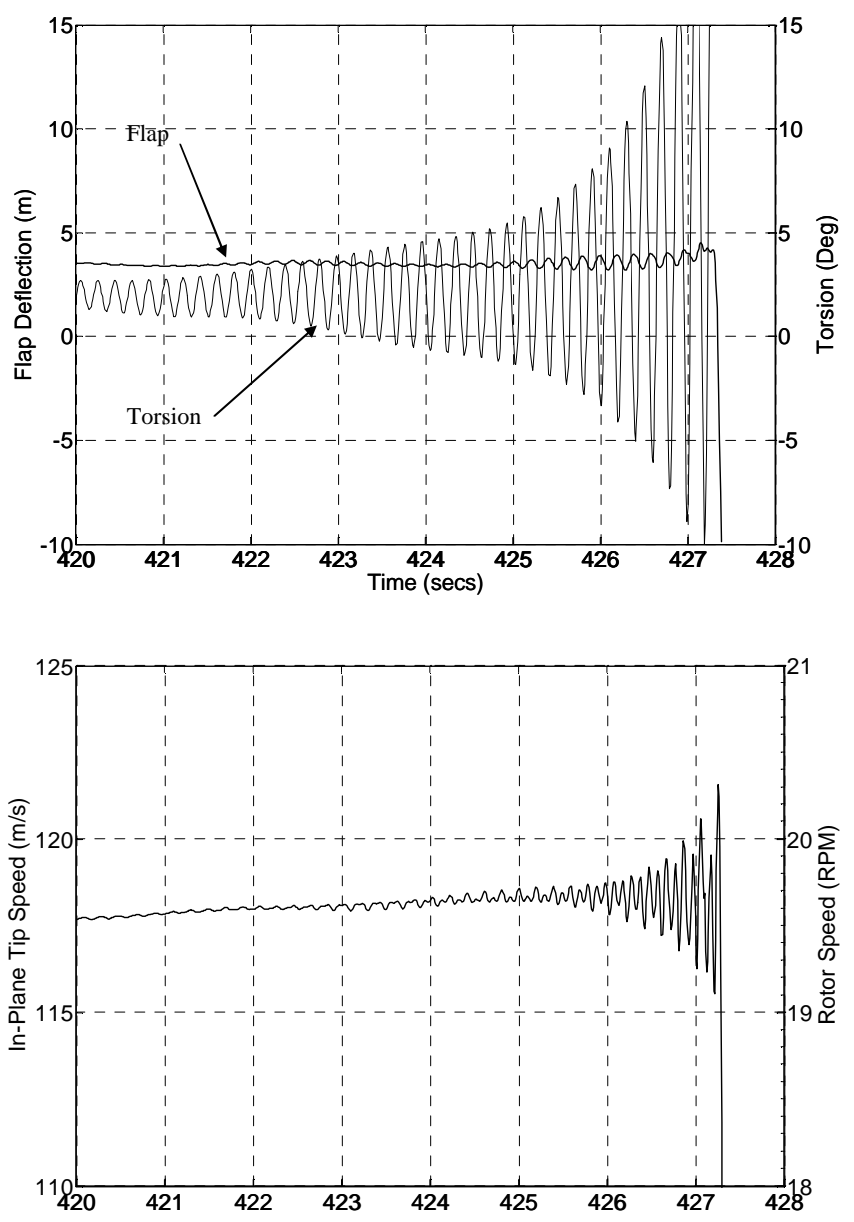

Figure 4. Exhibited Classical Flutter at mean wind speed of $10 \mathrm{~ms}^{-1}$ for increasing rotor speed (Flutter tip speed $118 \mathrm{~ms}^{-1}$ or 20RPM)

tip speed has an oscillating value since in is measured in the edgewise plane.

The distinguishing feature of Flutter, as can be viewed, is the increasing amplitudes of both torsion and flap to a point where in practical terms, failure of the blade would occur. It is shown the deflections go well beyond normal limits, and can occur within a range of seconds to tens-of-seconds. The Flutter speed is defined at the tip speed where the increasing amplitudes first become evident, which for the case shown is seen to be approximately $118 \mathrm{~ms}^{-}$ ${ }^{1}$, equivalent to about 20RPM. 


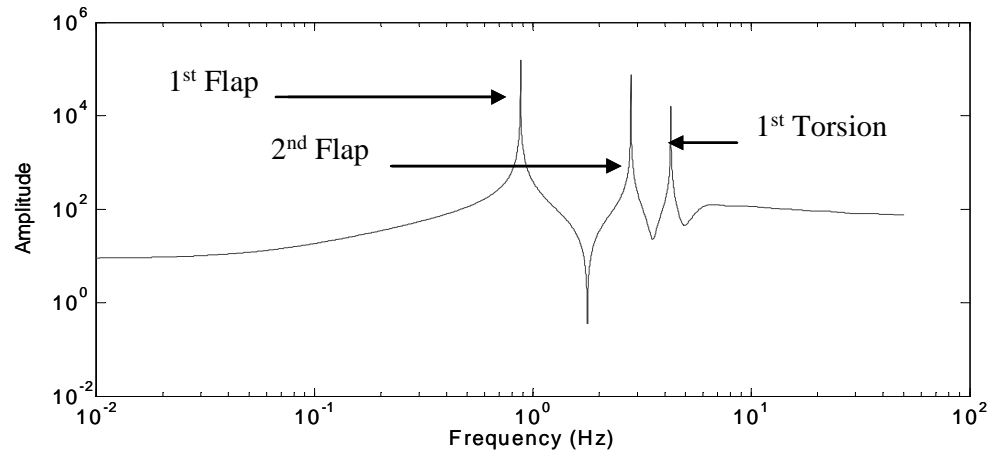

Figure 5. Spectrum of blade natural frequencies at operating rotor speed of 16 RPM (actual Flutter Speed 17.5 RPM)
The time simulations of Flutter are useful for viewing the blade response but no information about the blade modal interactions or system frequencies is available in this format. Therefore, the dynamics occurring near the Flutter speed were examined in the frequency domain in an attempt to verify at which frequency the flap and torsion modes are merging to cause Flutter, and whether the $1^{\text {st }}$ or $2^{\text {nd }}$ flap mode is the cause. In other studies on Flutter ${ }^{13}$, it is stated the second flapwise mode is usually interacting with the torsion mode because of the relatively high

torsional stiffness compared to the "soft" first flapwise mode. The system spectral response is analysed using a case with a mean wind speed of $15 \mathrm{~ms}^{-1}$. The Flutter speed in this instance was found to occur at $113 \mathrm{~ms}^{-1}$ equivalent to about 18.5 RPM. In the simulation, the operating conditions were brought as close to the Flutter limit as one could get without causing it to become unstable, which was to a rotor speed around 16RPM and a corresponding tip speed around $107 \mathrm{~ms}^{-1}$.

From the identified spectrum, given in Figure 5, it can be seen that the 1st blade flap mode at this rotational speed is slightly higher at about $0.9 \mathrm{~Hz}$ (from 0.85 non-rotating). The second blade flap mode has increased from $2.3 \mathrm{~Hz}$ to around $2.8 \mathrm{~Hz}$ and the torsion mode has reduced to $4.2 \mathrm{~Hz}$ from $5.6 \mathrm{~Hz}$ non-rotating. It appears the 2nd blade flap mode and 1st torsion mode are converging which would see them merge somewhere between $3 \mathrm{~Hz}$ and $4 \mathrm{~Hz}$ to cause Flutter. This value is in the vicinity of values found from other studies with similar sized blades and properties $^{3,13}$. This result gives some confidence in the methodology used to determine the Flutter limits.

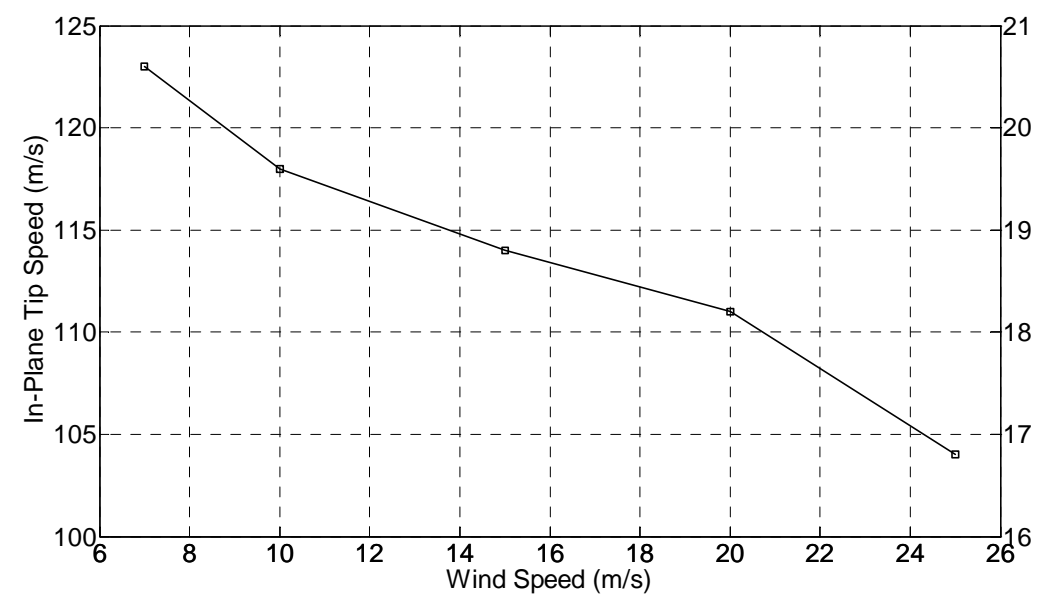

Figure 6. UpWind Turbine Flutter limits over given range of operating wind speeds

The Flutter velocity over the operating wind speed range of the UpWind turbine is given in Figure 6. The Flutter speed is found to decrease monotonically for increasing wind speed. The rotor speeds would have to be substantial for the UpWind turbine to enter a Flutter region (rated rotor speed is 12.7RPM). Obviously, this wind turbine design would most likely not experience Classical Flutter with its present blade structural properties and intended operating conditions. Note that Hansen ${ }^{3}$ finds a flutter speed of about 24RPM for a $5 \mathrm{MW}$ blade of $60 \mathrm{~m}$ span which is comparable to that found here. The torsion natural frequency was substantially higher however at $8 \mathrm{~Hz}$, compared to the currently used $5.6 \mathrm{~Hz}$, which might explain why Hansen found a higher Flutter speed.

\section{Centre of Gravity Offset Effects}

To study the sensitivity of the Flutter speed on the COG location, a case is examined for a wind speed of $15 \mathrm{~ms}^{-1}$ with the centre of gravity location exaggerated to be forward of the elastic shear axis while, ensuring this does not place the COG in front of the aerodynamic centre so that Flutter is still possible. The resulting effect is presented in Figure 7. It is shown with the centre of gravity placed forward of the elastic shear centre, the Flutter limit has been increased from approximately $113 \mathrm{~ms}^{-1}$ to $125 \mathrm{~ms}^{-1}$, an increase of $10 \%$. This therefore is in alignment with other Flutter analyses ${ }^{3}$, which show an increasing Flutter speed limit with such a position of the COG. 


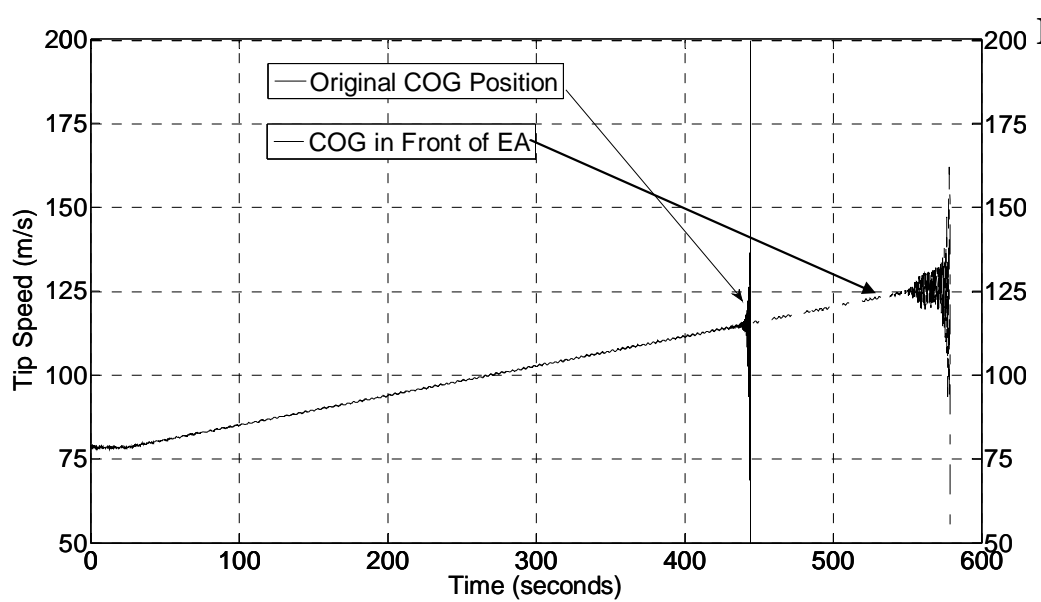

Figure 7. Extension of the Flutter limit due to placement of centre of gravity in front of elastic axis

\section{Smart Blade Design for Flutter Suppression}

In the preceding sections, the implementation of a dynamic model to capture the effects of Flutter is described and an attempt to determine the Flutter margins of the UpWind turbine (rigid hub and isolated blade analysis) is made. The outcome of the analysis suggested a current $5 \mathrm{MW}$ wind turbine is suitably far from the Flutter limits in its intended operating conditions.

It is now interesting to explore whether the Flutter of a blade can be controlled using a trailing edge flap (TEF), or otherwise called a 'smart' blade, such that it is possible to stabilise a blade temporarily in the Flutter zone or even stabilising for full operation within the zone. Evidence of this technique to stabilize Flutter could be very useful for future wind turbine designers as likely more flexible machines 10MW and beyond will be the industries future.

To this end, this final section aims to show through using simple control analysis techniques (e.g. Proportional, Integral or Derivative - PID controllers), it is possible to mitigate against Flutter and therefore potentially other known instabilities using a trailing edge flap. The intention is not to design a fully operational and optimised controller over the full gamete of wind turbine operating conditions, but rather to illustrate it might be achievable and warrant more investigation in a more detailed analysis using both full wind turbine aeroelastic analysis and rigorous controller design.

\section{A. Trailing Edge Flap Controller Design}

A general discussion of the airfoil model that includes the effect of trailing edge flaps is given in section II. It is now desirable to implement a control scheme for actuation of the TEF such that when the rotor experiences Flutter, the control scheme will act to keep the wind turbine stable. The goal is to design a simple feedback controller, such as using Proportional, Integral or Derivative action on the error of the desired system state to show the feasibility of using TEFs to control Flutter, and perhaps even other instabilities. The items addressed for the design of the Flutter suppression mechanism in this study are:

- Choice of feedback for the controller

- Implementation of a flap actuator with given frequency and damping characteristics with output of position, velocity and acceleration

- System identification techniques to create a linearised version of the total aeroelastic model for a given operational mode

- Controller design using root locus and frequency response analysis

The controller is not designed over the full wind turbine operating conditions, but rather a single condition is chosen where Flutter is evident to test the outcome of the smart blade. For convenience in carrying out the simulations, it was decided to reduce the blade properties to induce Flutter more readily. Two test cases are used to induce Flutter-one for increasing rotor speed to the Flutter point as previously, and another by using a step input in rotor speed close to the instability limit.

\section{State Feedback Variable}

It is desirable to test a TEF with realistic feedback variables. Hence, since proven methods are currently available to measure blade acceleration on a real wind turbine, the feedback variable for input into the controller is chosen to be the blade tip flap (out-of-plane) acceleration. If it is proving difficult to obtain a satisfactory controller with such feedback, another option worth exploring could be to use the torsion degree of freedom, as this would also carry information of the Flutter instability with it.

American Institute of Aeronautics and Astronautics

092407 


\section{Trailing Edge Flap Actuator Design}

A standard dynamic actuator concept is employed wherein an applied voltage $\mathrm{V}$, is used to drive the actuator to the desired position with predefined frequency and damping characteristics to achieve a desired flap response. $\mathrm{V}$ is regulated according to the feedback variable governing the state of the system to provide the response of the trailing edge flap (TEF) required to equilibrate the system. The second order differential equation (12) is chosen to represent the TEF dynamics with feedback of position and velocity.

$$
\ddot{\delta}+(2 \xi \omega) \dot{\delta}+\omega^{2} \delta=\omega^{2} V
$$

where $\omega$ is the simulated frequency of the TEF and $\xi$ is the simulated damping in the actuator.

Eq. (12) can be represented in block diagram form to illustrate how the feedback of TEF position and velocity is used to achieve the desired TEF position. A general configuration for the actuator is adopted in this study as the focus is not to design a fully optimised controller with finely tuned dynamics. A suitable TEF frequency is required so the dynamics are fast enough to influence the system, while damping will ensure not too much overshoot occurs. The characteristics of the actuator used in the analysis are a TEF frequency of $20 \mathrm{~Hz}$ and damping of $0.1 \mathrm{~kg} / \mathrm{s}$.

This actuator configuration is placed within the simulation environment so system identification techniques ${ }^{14}$ can be applied to obtain a linearised model of the total system dynamics that is subsequently used to

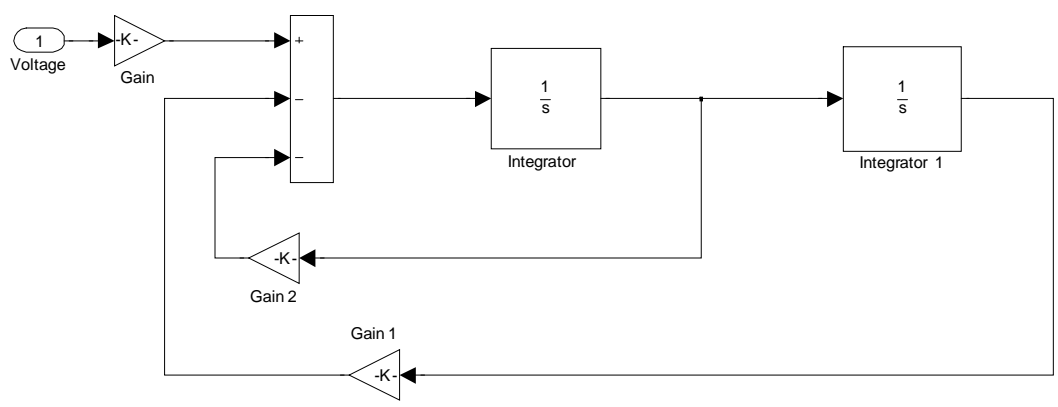

Figure 8. Block Diagram of Trailing Edge Flap Actuator with Feedback design the control algorithm for the Flutter suppression experiment.

\section{B. System Identification Near the Flutter Limit}

Classic control techniques for an actuated TEF to control Flutter are employed which follow these primary tasks:

- Select a feedback variable of the system which will describe the state of the system for the controller

- Obtain a linearised model of plant dynamics (e.g. single input - single output transfer function ) close to the state of that which will be controlled. The Box Jenkins approximation was used to build the model from the simulated data of the system.

- Analyse the model stability and use root locus / frequency response techniques to design a PID controller to effectively change the overall system behaviour (adding poles to the system)

A random TEF input is directed through the aerodynamic module and the blade response is measured as an open loop arrangement as shown in Figure 9. System Identification software available in Matlab is used to linearise the system (transfer function) and design the controller from a root locus analysis.

The idea is to modify the transfer function characteristics (poles, zeros, etc) to design a desired change into the original system dynamics for the

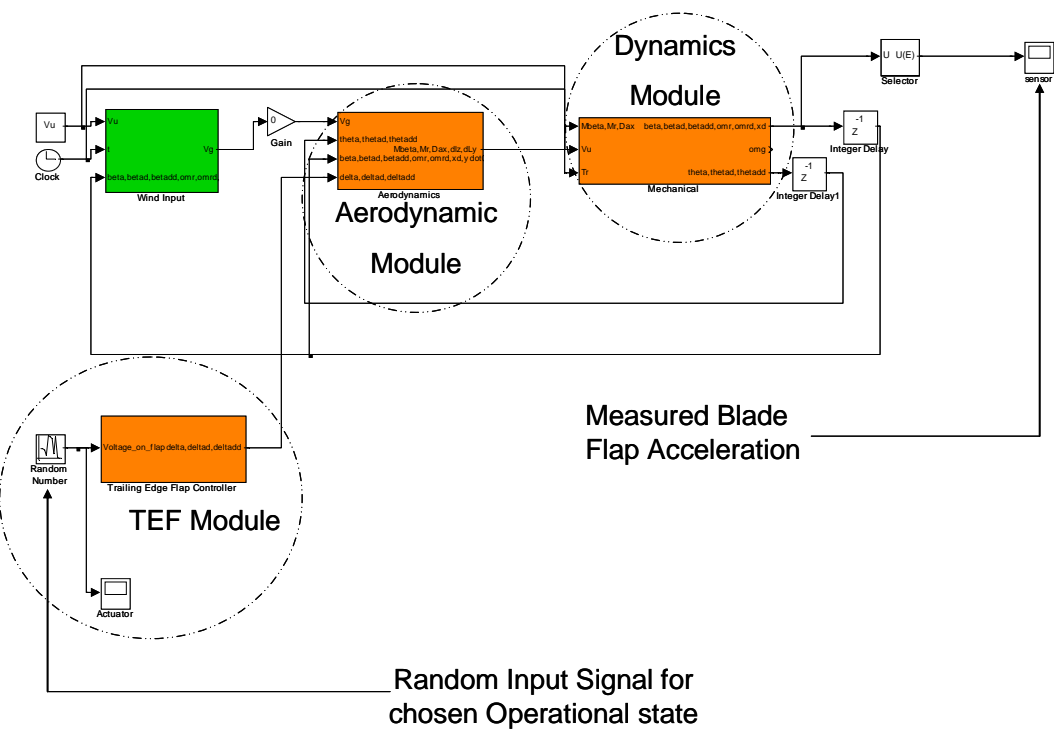

Figure 9. Experimental Set-up for Identification of System Dynamics

American Institute of Aeronautics and Astronautics 092407 


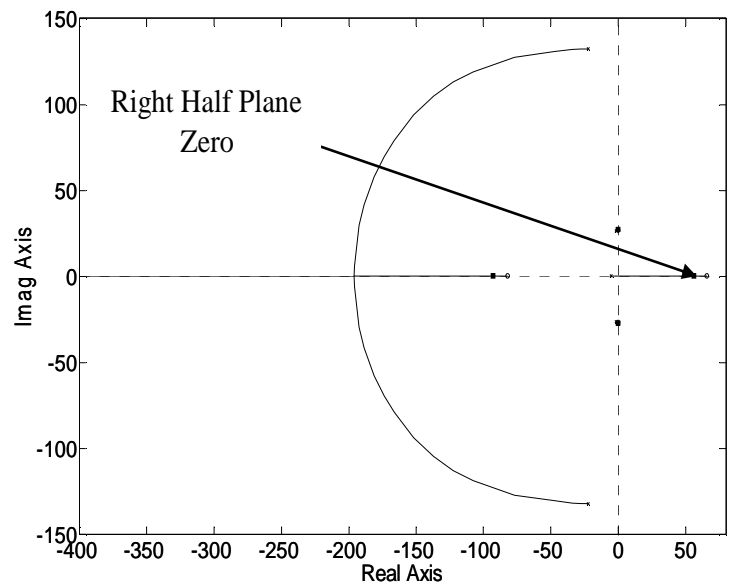

Figure 10. Root locus plot of the original system dynamics

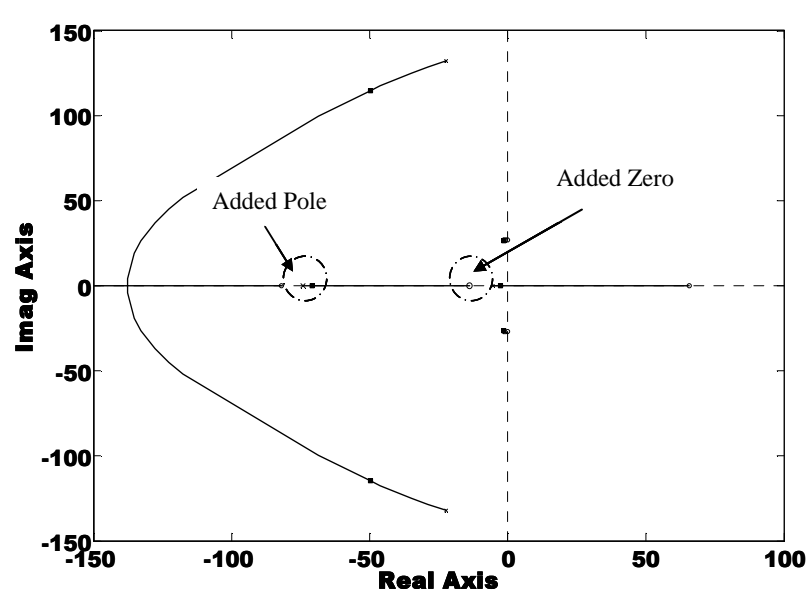

Figure 11. PID Compensator Root Locus Plot Showing Added Pole and Zero for a Desired Response given operating condition (i.e. design a controller). This modified transfer function, or rather, controller, can be inserted into the non-linear model of Figure 9 (to close the loop) and supply the desired state to the TEF actuator according to the feedback variable of blade tip flapping acceleration.

A single PID controller is experimented with to combat Flutter. The root locus plot of the original identified system, shown in Figure 10, shows the system to be open-loop unstable with both a pole and a zero in the right half plane. The pole could be moved through addition of gain but the same cannot be said for the zeros presence. In control system theory, it is known systems with right-half plane zeros are intrinsically difficult to control. The designed compensator from the identified system transfer function is given in Figure 11. This compensator can be exported into the non-linear model and tested in the condition it was designed for. Section V details the Flutter experiment set-up to test the above compensator to show the validity of using TEFs to control Flutter.

\section{Flutter Suppression Analysis}

\section{A. Experimental Set-up}

To induce the mechanism of Flutter at realistic rotor speeds, the UpWind blade properties are modified; blade torsional stiffness is reduced and the centre of gravity is placed further aft of the elastic -see Table 2. A wind turbine operating region is chosen for a zero pitch angle at a wind speed of $8 \mathrm{~ms}^{-1}$ to be sure the simulation is as realistic as possible (i.e. to eliminate control issues of the wind turbine as it approaches rated wind speed). The new properties of the blade, along with the dimensions of the TEF are given in Table 2.

It is appreciated both the controller dynamics and TEF dimensions (chord and span) would be important in obtaining an overall optimised configuration to control Flutter. The,present study is limited however to using approximate values suitable for the purpose of merely showing if Flutter can be stabilised with a TEF. It is left for future studies to focus on optimisation of controlling the instability.

The aspects that are considered in choosing the TEF dimensions to keep the results realistic are a minimal spanwise extent, starting from the tip of the blade going inboard, and a ratio of TEF chord to aerofoil chord between 0.1 and 0.25 . It is considered important to use as little span as possible because the TEF is assumed to remain rigid in flapwise bending relative to the aerofoil (i.e. it does not deflect according to the mode shape of the aerofoil). The tip region is used because it is the most effective region for impacting the flapwise deflections. It is desired to keep a small TEF chord to aerofoil chord ratio such that the structural integrity of the blade is maintained and to minimise the size of the TEF such that practically sized actuating power is required, thereby reducing bending moments about the hinge

Table 2. Wind turbine, blade and TEF parameters defining Flutter experiment

\begin{tabular}{|l|c|}
\hline Wind Speed & $8 \mathrm{~ms}^{-1}$ \\
\hline Rotor Speed & $8.5 \mathrm{RPM}$ \\
\hline Torsion Frequency & $4 \mathrm{~Hz}$ \\
\hline $\begin{array}{l}\text { COG Offset (\% extra } \\
\text { original value) }\end{array}$ & $30 \%$ \\
\hline $\begin{array}{l}\text { TEF Frequency } \\
\begin{array}{l}\text { TEF Chord Length } \\
\text { (\% of aerofoil chord) }\end{array}\end{array}$ & $20 \%$ \\
\hline $\begin{array}{l}\text { TEF Span Length }(\% \\
\text { of aerofoil span) }\end{array}$ & $30 \%$ \\
\hline
\end{tabular}


points.

Two methods have been employed to test the controllability of the Flutter limit. The first is to take advantage of the reduced blade properties by using a step input on the rotor speed to induce Flutter. The response is examined closely to determine if it is in fact Flutter occurring. Based on the analysis of Flutter behaviour in preceding sections, it is deemed the blade is sent into a classical Flutter mode through a step increase from 8.5 RPM to 9.6 RPM.

The second method is to validate the Flutter mode of the previous, whereby once again the rotor is allowed to gradually speed up to the Flutter point with the controller in place. It would be expected the Flutter speed to be quite low, since the relatively small step input in rotor speed in the previous case was enough to cause the instability. This case also tests how the controller performs for continually changing system dynamics and gives an indication how far the Flutter limit is extended with TEF control.

\section{B. Trailing Edge Flap Performance}

Figure 12 shows the performance of the TEF on suppressing Classical Flutter for the first case mentioned above. Shown is the simulation without the controller in place to preview the occurrence of the instability, followed by a simulation with the controller installed.

After a step input (at 10 seconds simulation time) on the rotor speed, the response of torsion and flapwise deflections start to drift, increasing in magnitude until rapid Flutter occurs within 5 seconds after experiencing the disturbance. For the simulation with added controller, after the disturbance again the drift occurs to the same point where Flutter is reached, but now the TEF starts to act and stabilises the response to reach a new equilibrium of elastic torsion of about 6 degrees (up from $\sim 4.5$ degrees) and flap deflection of approximately $5 \mathrm{~m}$ (up from $\sim 4 \mathrm{~m}$ ).

Figure 13 shows the results again for the case of an installed controller for the blade flapping and TEF response to a step input in rotor speed but with extended time history to show the stabilised response. The TEF has a maximum deflection of approximately 23 degrees, reaching an equilibrium oscillatory amplitude of about 10 degrees. This experiment shows a positive result for stabilising the response of the turbine which has entered a Flutter zone using controlled TEFs.

The same controller is now applied for the second case of increasing rotor speed to and beyond the Flutter speed, see Figure 14. The Flutter speed of the modified blade with no controller is approximately reached at $66 \mathrm{~ms}^{-1}$, at which sudden amplitude growth in torsion and flap occurs causing the simulation to fail. With the controller in place, it is shown the Flutter limit is increased as it is being suppressed, but in this case, the system is slowing growing in amplitude, with the TEF unable to reach equilibrium. This could be caused by a few reasons; one being that the system is always slowly accelerating in rotor speed, meaning the systems dynamics are shifting away from that which the controller was designed for. Another reason may be due to an edgewise instability which seemed to be more pronounced as the rotor speed increased far beyond the normal operation speed. It should be remembered that this test case uses altered blade properties, so the dynamics of the blade may not behave as expected, especially at higher than intended rotor speeds, so large edgewise deflections might be expected.

The larger edgewise deflections show through to the coupled torsion and flap response by the increasing amplitude shown in the right side of Figure 14. Therefore it could be possible that without the edgewise instability, the controller may keep the system from slowly increasing in amplitude. To verify this problem, a simulation is carried out so that the rotor speed became constant at some point within the Flutter zone, rather than continuing to increase. The effect is that the system shows more stability, but still a very slowly building edgewise instability results. The conclusion therefore is that while Flutter is suppressed, other dynamics are interfering with the control of the wind turbine dynamics.

In any event, the result still shows an extension of the Flutter boundary well beyond that without the controller and gives evidence to suggest a more complex, thoroughly designed controller with an optimised controller and TEF flap assembly is a suitable means to mitigate against Classical Flutter instability problems on wind turbines. 


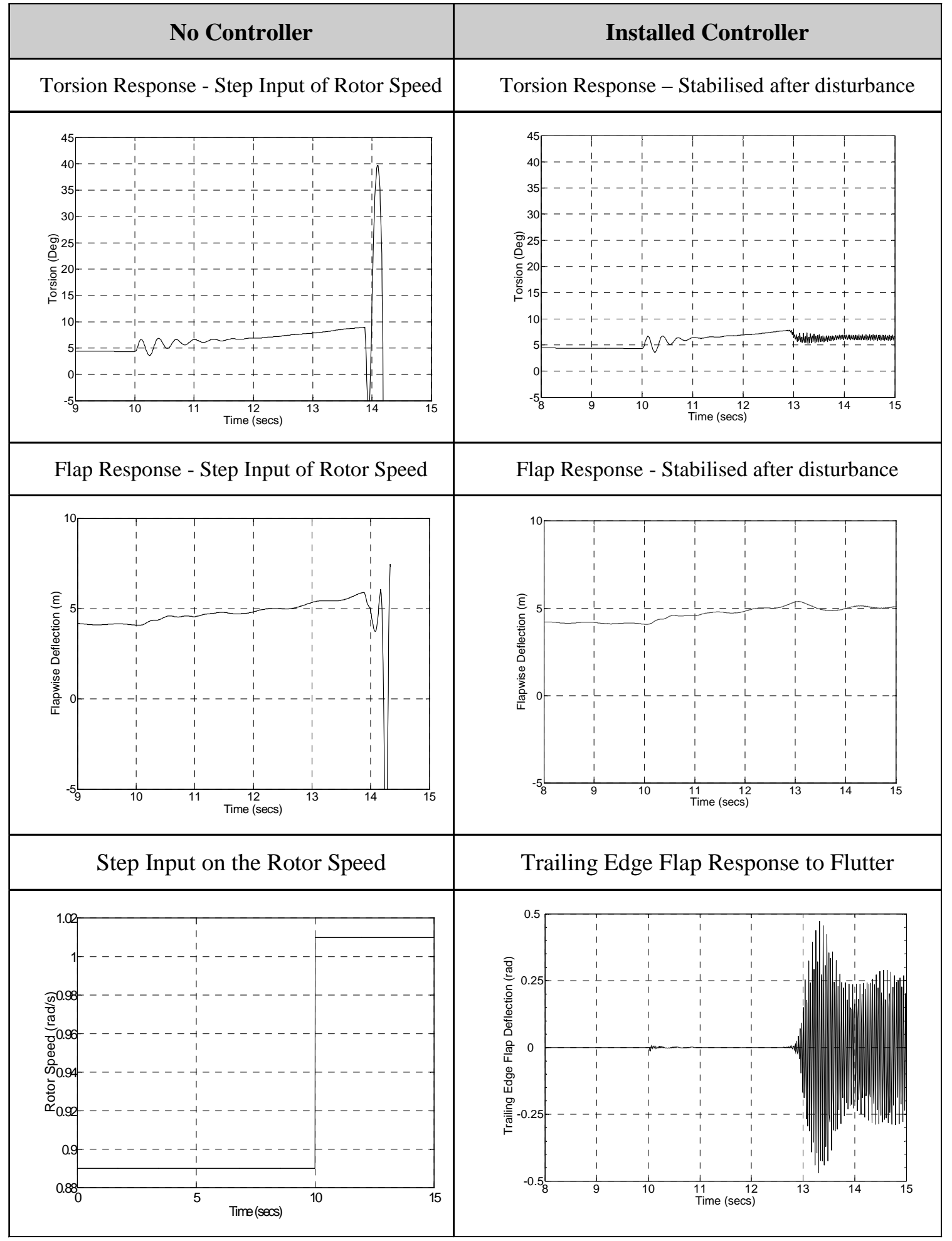

Figure 12. Induced Flutter for Step Input on Rotor Speed (Step Input at 10 secs) and TEF Controller Response (Bottom-Right) 


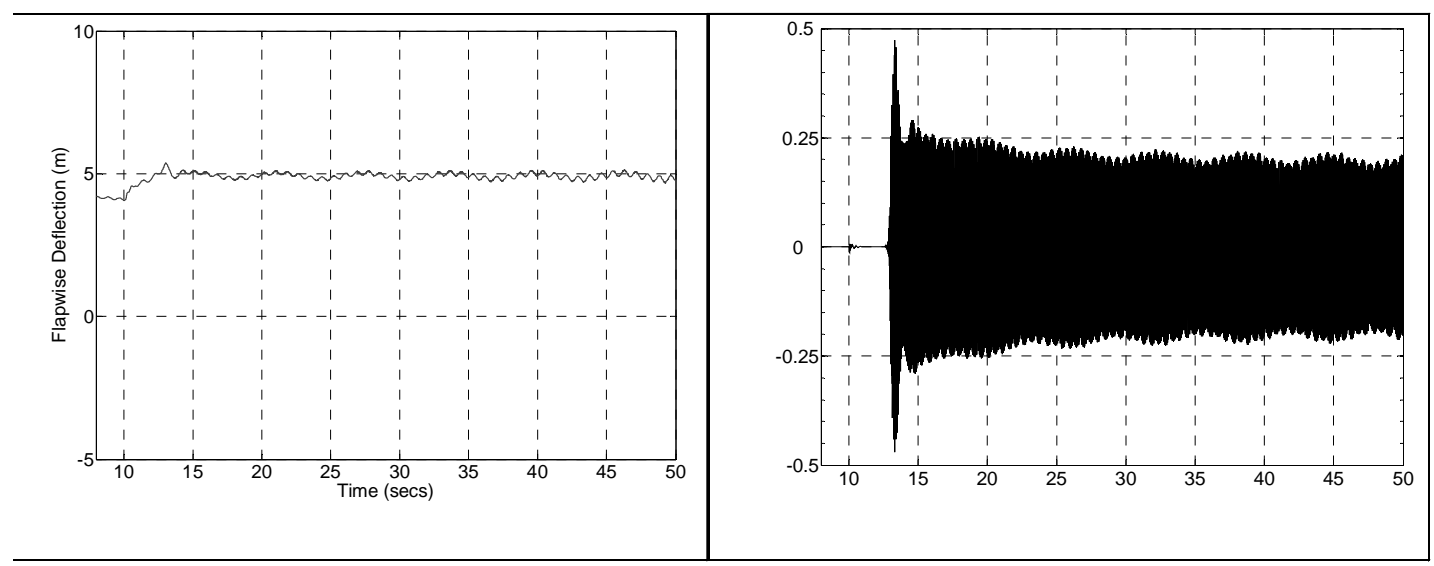

Figure 13. Expanded Time History for Flap (left) \& TEF (right) Response to a Step Input on

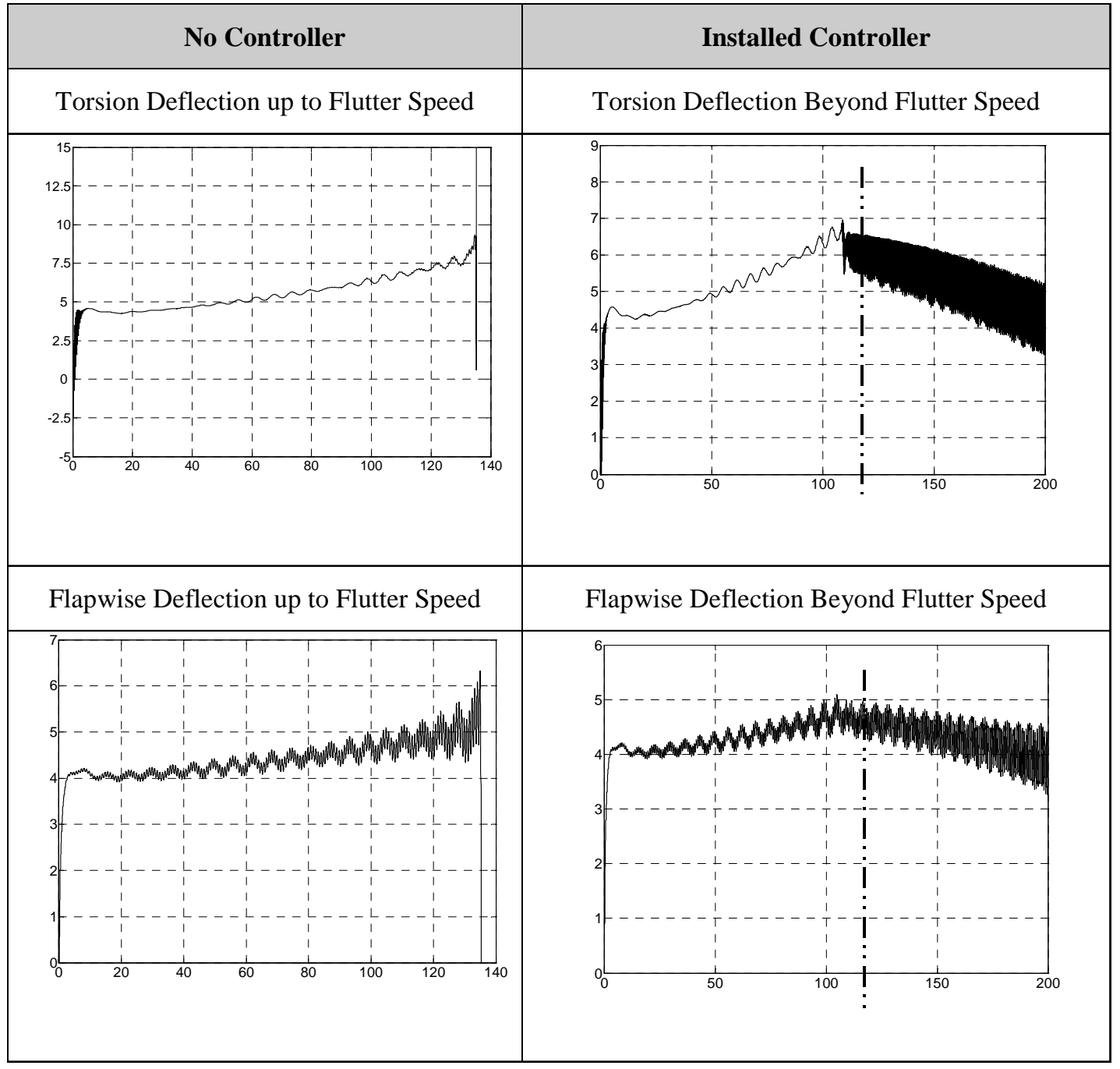

Figure 14. Induced Flutter and Control for Ramp Up of Rotor Speed

American Institute of Aeronautics and Astronautics 092407 


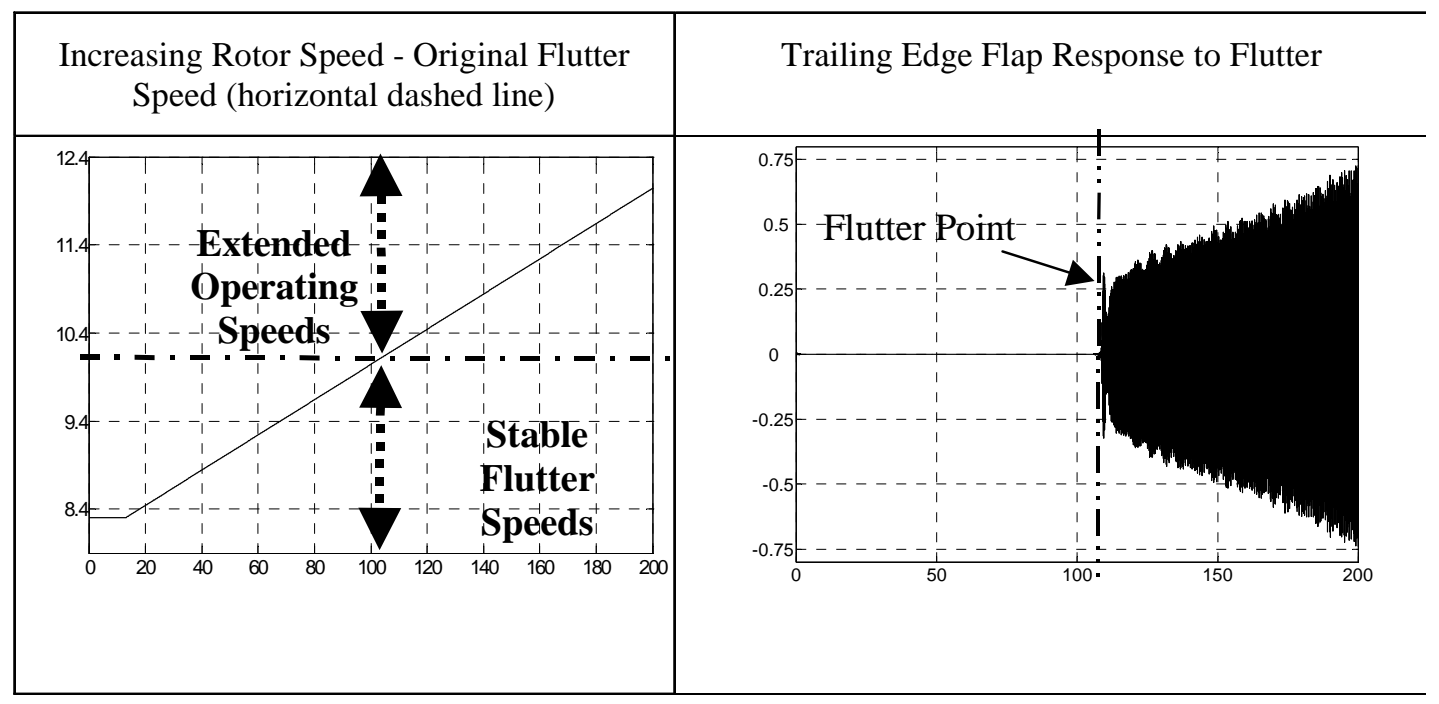

Figure 14 (Continued). Induced Flutter and Control for Ramp Up of Rotor Speed

\section{Conclusion}

In the current analysis, the following items have been addressed in terms of fulfilling the goals and objectives initially set out to investigate the feasibility of using trailing edge flaps to mitigate against the Classical Flutter instability:

- A simplified aeroelastic model comprising of a modal analsysis and BEM theory module has been developed for determination of the forces and response of the rotor. The equations of motion are represented through the generalised coordinate method and virtual work principle for a discretised beam. An aerofoil model is employed, based on Theodorsen's model, that is capable of determining the lift coefficient for arbitrary aerofoil and TEF deflections .

- A rigid tower, one-bladed version of the 5MW UpWind turbine (122m diameter), with all blade sectional properties and operating characteristics as prescribed, has been investigated for its Classical Flutter instability limits.

- Finally, it has been shown that implementing trailing edge flaps does have the potential to stabilise against the Classical Flutter effect. For a given trailing edge flap span and chord width, it was possible to show the modified wind turbine entering into a Flutter mode and being stabilised by trailing edge flap deflection frequencies of $20 \mathrm{~Hz}$ and angles around 13 degrees. For one scenario in particular, it was shown the wind turbine was still stabilised for an increase in rotor speed of 3RPM beyond its original Flutter limit.

\section{Recommendations}

The results presented for the performance of TEFs as a stability shaping device have been positive in the theoretical sense, and in the author's opinion, warrants more investigation into their feasibility for future wind turbine designs. The current study has used a simplified analysis and leaves room for more rigorous testing of TEFs. Some points to consider in any subsequent analysis are given below:

- The aeroelastic model should be expanded to include the whole turbine structure, such as drive train and tower dynamics. This includes modelling three blades, rotor coning and tilt. Hansen ${ }^{2}$ has shown the dynamics of the whole turbine structure influence the Flutter limits.

- More testing on Flutter effects using more detailed wind fields, such as with tower shadow, wind shear and turbulence effects.

- Trailing edge flap dynamics needs to be included with blade dynamics, i.e. need to model TEF deformation relative to aerofoil due to inertia and elastic forces. This will give a more realistic description of the aerodynamics on the blade and allow optimised design of flap surface. A more detailed analysis needs to be 
made on where the resulting forces and moments are produced with a TEF, as these may impact on controllability.

- More focus on the realistic simulation of a type of actuator with specific mechanical properties to give realistic output for magnitudes of flap angles and frequency for practical Flutter suppression.

- More analysis on the optimum span and chord width of TEF for maximum load control and minimum actuator power.

- Incorporate more complex controller techniques, such as multiple-input-output controllers. This might make for better control over the Flutter instability which was a limiting factor in this analysis. The author can recommend the material presented in Verhaegen and Verdult ${ }^{15}$ for an introduction into MIMO system analysis as could be applied in an extension to the present study.

\section{References}

${ }^{1}$ Pavel, M.D. \& Schoones, M.M.J. (1999), "Literature survey on Aeromechanical Instabilities for helicopters and wind turbines", TUDelft, Novem project no. 224.740-9854.

${ }^{2}$ Hansen, M.H.(2002), "Vibrations of a Three-Bladed Wind Turbine Rotor due to Classical Flutter". AIAA, A02-14513 (48), 256-66.

${ }^{3}$ Hansen, M.H. (2007), “Aeroelastic Instability Problems for Wind Turbines”, von Karmen Institute for Fluid Dynamics, Lecture Series 2007-05.

${ }^{4}$ Van Holten, Th. (2006), "Energy Flow Considerations, An Educational Tool to Clarify Aeroelastic Phenomena", Conference Paper, TUDelft.

${ }^{5}$ Pavel, M.D. (1999), “An investigation of the Rotor-Tower Instability of the KEWT Wind Turbine”, TUDelft, Novem project no $224.740-9854$.

${ }^{6}$ Van Holten, Pavel, M.D. \& Smits, G.N., "The Influence of Scale Effects on the Aeroelastic Stability of Large Wind Turbines", Faculty of Aerospace Engineering, Delft University of Technology, Delft.

${ }^{7}$ Leishman, J.G. (1994). "Unsteady Lift of a Flapped Airfoil by Indicial Concepts”. AIAA Journal, Vol. 31, No. 2, $288-296$.

${ }^{8}$ Clough, R.W. (1975), Dynamics of Structures, McGraw-Hill.

${ }^{9}$ Hansen, M.H (2003). Aerodynamics of Wind Turbines, James \& James Ltd.

${ }^{10}$ Bielawa, R.L. (1992), Rotary Wing Structural Dynamics and Aeroelasticity, AIAA Education Series, US

${ }^{11}$ Van Langen, P.J. (2007), "Aeroleastic Analysis of the UpWind reference wind turbine" (Draft), ECN, ECN-E-07-000

${ }^{12}$ Rasmussen, F. Hansen, M.H, Thomsen, K, Larsen, T.J, Bertagnolio, F., Johansen, J., Madsen, H.A., Bak, C. \& Hansen, A.M. (2003), "Present Status of Aeroelasticity of Wind Turbines", Wind Energy, Vol 6, pp. 213-228.

${ }^{13}$ Borglund, D. \& Kuttenkeuler, J. (2002), "Active Wing Flutter Suppression Using a Trailing Edge Flap, Journal of Fluids and Structures", Vol. 16(3), pp. 271-294.

${ }^{14}$ Van den Hof, P.M.J (2004), System Identification, Delft Centre for Systems and Control, Delft.

${ }^{15}$ Verhaegan, M. \& Verdult, V. (2007), Filtering and System Identification: An Introduction, Cambridge Univ Pr.

${ }^{16}$ Glauert, H., (1963), Airplane Propellers, Aerodynamic Theory, W. F. Durand, ed., Dover, New York.

${ }^{17}$ Hansen, M.O.L., Sorensen, J.N., Voutsinas, S., Sorensen, N. \& Madsen, H.Aa (2006), Elsevier, "Progress in Aerospace Sciences" Vol. 42, pp. 285-330.

${ }^{18}$ Leishman, J.G. (2002), "Challenges in Modelling the Unsteady Aerodynamics of Wind Turbines", Wind Energy, Vol 5, pp. 85-132.

${ }^{19}$ Buhl, T., Gaunaa, M. and Bak, C., "Potential Load Reduction Using Airfoils with Variable Trailing Edge Geometry", Journal of Solar Energy Engineering, Vol. 127, pp. 503-516, 2005 